\title{
Agents that affect cAMP levels or protein kinase $A$ activity modulate memory consolidation when injected into rat hippocampus but not amygdala
}

L. Bevilaqua ${ }^{1}$, P. Ardenghi ${ }^{1}$, N. Schröder ${ }^{1}$, E. Bromberg ${ }^{1}$,

J. Quevedo' ${ }^{1}$, P.K. Schmitz ${ }^{1}$, M. Bianchin ${ }^{1}$, R. Walz',

E. Schaeffer ${ }^{1}$, J.H. Medina ${ }^{2}$ and I. Izquierdo ${ }^{1}$

\author{
${ }^{1}$ Centro de Memória, Departamento de Bioquímica, Instituto de Ciências Básicas \\ da Saúde, Universidade Federal do Rio Grande do Sul, 90035-003 Porto Alegre, \\ RS, Brasil \\ ${ }^{2}$ Laboratorio de Neurorreceptores, Instituto de Biología Celular, Facultad de Medicina, \\ Universidad de Buenos Aires, 1121 Buenos Aires, Argentina
}

\section{Correspondence \\ I. Izquierdo \\ Departamento de Bioquímica \\ Instituto de Biociências, UFRGS \\ 90046-900 Porto Alegre, RS \\ Brasil \\ Fax: 55 (051) 316-3505}

Presented at the XII Annual Meeting of the Federação de Sociedades de Biologia Experimental, Caxambu, MG, Brasil, August 27-30, 1997.

Research supported by PRONEX, Brasil.

Received March 26, 1997 Accepted June 11, 1997

\begin{abstract}
Male Wistar rats were trained in one-trial step-down inhibitory avoidance using a 0.4-mA footshock. At various times after training $(0,1.5$, 3,6 and $9 \mathrm{~h}$ for the animals implanted into the CA1 region of the hippocampus; 0 and $3 \mathrm{~h}$ for those implanted into the amygdala), these animals received microinfusions of SKF38393 (7.5 $\mu \mathrm{g} / \mathrm{side})$, SCH23390 $(0.5 \mu \mathrm{g} / \mathrm{side})$, norepinephrine $(0.3 \mu \mathrm{g} / \mathrm{side})$, timolol $(0.3$ $\mu \mathrm{g} / \mathrm{side}), 8$-OH-DPAT ( $2.5 \mu \mathrm{g} / \mathrm{side})$, NAN-190 (2.5 $\mu \mathrm{g} / \mathrm{side})$, forskolin $(0.5 \mu \mathrm{g} / \mathrm{side})$, KT5720 (0.5 $\mu \mathrm{g} / \mathrm{side})$ or 8 -Br-cAMP (1.25 $\mu \mathrm{g} / \mathrm{side})$. Rats were tested for retention $24 \mathrm{~h}$ after training. When given into the hippocampus $0 \mathrm{~h}$ post-training, norepinephrine enhanced memory whereas KT5720 was amnestic. When given $1.5 \mathrm{~h}$ after training, all treatments were ineffective. When given 3 or $6 \mathrm{~h}$ post-training, 8-BrcAMP, forskolin, SKF38393, norepinephrine and NAN-190 caused memory facilitation, while KT5720, SCH23390, timolol and 8-OHDPAT caused retrograde amnesia. Again, at $9 \mathrm{~h}$ after training, all treatments were ineffective. When given into the amygdala, norepinephrine caused retrograde facilitation at $0 \mathrm{~h}$ after training. The other drugs infused into the amygdala did not cause any significant effect. These data suggest that in the hippocampus, but not in the amygdala, a cAMP/protein kinase A pathway is involved in memory consolidation at 3 and $6 \mathrm{~h}$ after training, which is regulated by $\mathrm{D}_{1}, \beta$, and $5 \mathrm{HT} 1 \mathrm{~A}$ receptors. This correlates with data on increased post-training cAMP levels and a dual peak of protein kinase A activity and CREB-P levels (at 0 and 3-6 h) in rat hippocampus after training in this task. These results suggest that the hippocampus, but not the amygdala, is involved in long-term storage of step-down inhibitory avoidance in the rat.
\end{abstract}

Key words

- Memory formation

- Memory modulation

- Hippocampus

- Amygdala

- cAMP/PKA/CREB-P pathway

- Dopamine $\mathrm{D}_{1}$ receptors

- ß-Adrenoceptors

- 5HT1A receptors 
The cyclic adenylyl monophosphate (cAMP)/PKA/CREB-P signalling pathway plays a key role in the link between the early phase of memory formation and long-term neural plasticity (1). The CREB factor becomes active when phosphorylated (CREB$\mathrm{P})$ and this phosphorylation is mediated by cAMP-dependent protein kinase A (PKA) (2). The cAMP/PKA/CREB-P pathway leads to gene activation crucial for the persistence of memory of inhibitory avoidance in rats beyond 3-6 h (3).

One-trial step-down inhibitory avoidance learning in rats depends on the hippocampus and amygdala (4). At 3-6 h after training, step-down avoidance is followed by an increase in cAMP levels in the hippocampus (5), CREB-P (3), and PKA activity (3). Onetrial inhibitory avoidance in rats is also followed by hippocampal ultrastructural changes (6). Some evidence (intra-amygdala infusion of AMPA receptor antagonist impairs retrieval) has suggested that the amygdala may be involved in storage together with the hippocampus. However, there is also evidence suggesting that the amygdala may instead modulate storage processes in the hippocampus and elsewhere (7).

Serotoninergic, dopaminergic and noradrenergic fibers innervate both hippocampus and amygdala and 5HT1 A, dopamine $\mathrm{D}_{1}$ and $B$-adrenergic receptors are present in both structures (8). These pathways and receptors play a role in the regulation of emotions and mood (9).

To address the involvement of the above structures and receptors in memory formation, we studied the effect of various drugs infused into the hippocampus or the amygdala at different times post-training: SKF38393 (a dopamine $D_{1}$ receptor agonist; $7.5 \mu \mathrm{g}$ / side), SCH23390 (a dopamine $\mathrm{D}_{1}$ receptor antagonist; $0.5 \mu \mathrm{g} / \mathrm{side}$ ), norepinephrine (a B-adrenoceptor agonist; $0.3 \mu \mathrm{g} /$ side $)$, timolol (a B-blocker; $0.3 \mu \mathrm{g} /$ side), 8-OH-DPAT (a 5HT1 A receptor agonist; $2.5 \mu \mathrm{g} /$ side), NAN190 (a 5HT1A receptor antagonist; $2.5 \mu \mathrm{g}$ / side), the PKA inhibitor, KT5720 (0.5 $\mu \mathrm{g}$ / side), 8-Br-cAMP (1.25 $\mu \mathrm{g} /$ side) and the adenylyl cyclase stimulator, forskolin (0.5 $\mu \mathrm{g} /$ side), infused bilaterally into the hippocampus or into the amygdala at various times after one-trial inhibitory avoidance training (10). Control groups received vehicle $(20 \%$ dimethylsulfoxide in saline) or saline depending on which was used to dissolve the drugs.

Under deep thionembutal anesthesia, all animals had 27-g cannulae implanted bilaterally into the CA1 region of the hippocampus, or at the junction between the basolateral and the central nucleus of the amygdala. Coordinates were A -4.3, L $\pm 4.0, \mathrm{~V} 3.4$ for CA1 and $\mathrm{A}-2.3, \mathrm{~L} \pm 4.5, \mathrm{~V} 8.4$ for the amygdala, according to the atlas of Paxinos and Watson (11). The infusion procedures were carried out through a tight-fitting inner probe placed within the guide cannulae at appropriate times $(0,1.5,3,6$ and $9 \mathrm{~h}$ posttraining for animals implanted into the hippocampus; 0 and $3 \mathrm{~h}$ post-training for those implanted into the amygdala) (12). Two to $24 \mathrm{~h}$ after the end of the behavioral procedures, the animals were sacrified by decapitation. Anatomical verification of cannula placements was carried out and only behavioral results for animals with correct cannula placement (i.e., within $1 \mathrm{~mm}^{2}$ of the intended sites) were considered (13).

One-trial step-down avoidance was chosen for three reasons: a) it involves a simple and quick form of learning in which posttraining memory processing can be measured quite precisely (14); b) its post-training pharmacology and biochemistry are well known $(4,15)$, including information related to the cAMP/PKA/CREB-P pathway (1), and c) it is representative of the type of events that are "instantly encoded" in which this pathway has been best studied (16).

Training session step-down differences among groups were not significant at the $\mathrm{P}=$ 0.05 level by Kruskal-Wallis analysis of variance. Results of test session step-down la- 
tency measurements are shown in Tables 1 (hippocampus) and 2 (amygdala). Trainingtest latency differences were significant in all groups (Mann-Whitney U-test, $\mathrm{P}<0.002$ ) except those that received KT5720 in the hippocampus 0,3 or $6 \mathrm{~h}$ post-training, or 8OH-DPAT, timolol, and SCH23390 in the hippocampus 3 or $6 \mathrm{~h}$ post-training, thus indicating good retention levels in all groups except these.

When given into the hippocampus $0 \mathrm{~h}$ after training, only two of the treatments showed an effect: norepinephrine, which caused retrograde facilitation, and KT5720, which caused retrograde amnesia. All treatments were ineffective when given $1.5 \mathrm{~h}$ after training. When given 3 or $6 \mathrm{~h}$ after training into the hippocampus, SKF38393, norepinephrine, NAN-190, 8-Br-cAMP and forskolin caused memory facilitation, and SCH23390, timolol, 8-OH-DPAT and KT5720 were amnestic. When given $9 \mathrm{~h}$ after training into the hippocampus, again all the treatments were ineffective (Table 1).

Only one treatment was effective by intra-amygdala infusion: norepinephrine caused retrograde facilitation when given 0 $\mathrm{h}$ post-training. All other treatments, including norepinephrine given at $3 \mathrm{~h}$, were without any effect on retention scores (Table 2).

There were clearly two time "windows" for drug action in the hippocampus. The first one was at $0 \mathrm{~h}$ after training and coincided with the early labile phase of memory (7). The second one ( 3 to $6 \mathrm{~h}$ ) coincided with an increase in cAMP $(3,5)$, PKA activity $(3,5)$ and CREB-P levels (3) described in the hippocampus following training in this task. This second "window" slightly precedes a peak of hippocampal glycoprotein synthesis (8) and ultrastructural changes in the dentate gyrus (6) observed after similar tasks. It is tempting to suggest that the second "window" may be linked to cell adhesion changes involved in long-term storage.

As is known, serotonergic, dopaminergic and noradrenergic endings and $5 \mathrm{HT} 1 \mathrm{~A}, \mathrm{D}_{1}$ and $\beta$ receptors are found throughout the hippocampal formation. These pathways and receptors are involved in central mechanisms of emotions and mood (9). Brain diseases in which one of these systems is deficient are often accompanied by cognitive disorders (9). This may be related to the long duration of the period during which memory is exposed and susceptible to the influence of these modulators ( $3 \mathrm{~h})$ and to the strength of this modulation. When given 3 to $6 \mathrm{~h}$ after training, SCH23390, timolol, 8-OH-DPAT and KT5720 induced full retrograde amnesia comparable to that observed with imme-

Table 1 - Median test session latency in groups infused bilaterally into the hippocampus with the following drugs: 8-OH-DPAT (DPAT), NAN-190 (NAN), norepinephrine (NE), timolol (TIM), SKF38393 (SKF), SCH23390 (SCH), 8-Br-CAMP (cAMP), KT5720 (KT), forskolin (FOR), vehicle (VEH) and saline (SAL).

${ }^{*} \mathrm{P}<0.002$ compared to saline control group (all drugs except KT and FOR) or vehicle group (KT and FOR) (two-tailed Mann-Whitney U-test). $\mathrm{N}=$ 9-12 per group. Note that when treatments were given immediately after training $(0 \mathrm{~h}), \mathrm{NE}$ caused retrograde memory facilitation and KT caused retrograde amnesia. When given 1.5 or $9 \mathrm{~h}$ after training, all treatments were ineffective. When infused 3 or $6 \mathrm{~h}$ post-training, NAN, NE, SKF, CAMP and FOR induced a pronounced facilitation. At the same time, DPAT, TIM, SCH and KT caused full retrograde amnesia.

\begin{tabular}{lccccl}
\hline \multirow{2}{*}{ Drug } & \multicolumn{5}{c}{ Latency (min) } \\
\cline { 2 - 6 } & \multicolumn{5}{c}{ Time after injection } \\
\cline { 2 - 6 } & $0 \mathrm{~h}$ & $1.5 \mathrm{~h}$ & $3 \mathrm{~h}$ & $6 \mathrm{~h}$ & $9 \mathrm{~h}$ \\
\hline SAL & 55 & 50 & 51 & 54 & 52.5 \\
DPAT & 55 & 46 & $10^{*}$ & $5.5^{*}$ & 48 \\
NAN & 58.5 & 54 & $165^{*}$ & $180^{*}$ & 60 \\
NE & $180^{*}$ & 49 & $180^{*}$ & $180^{*}$ & 50.5 \\
TIM & 56 & 35 & $5^{*}$ & $6^{*}$ & 51 \\
SKF & 40 & 53 & $180^{*}$ & $180^{*}$ & 43.5 \\
SCH & 43 & 45 & $10^{*}$ & $11^{*}$ & 51 \\
CAMP & 38 & 46 & $166.5^{*}$ & $180^{*}$ & 57 \\
VEH & 49.5 & 63 & 51.5 & 58 & 51.5 \\
KT & $9 *$ & 38 & $10^{*}$ & $9^{*}$ & 58 \\
FOR & 53.5 & 52 & $151^{*}$ & $155.5^{*}$ & 48.5
\end{tabular}

Table 2 - Median test session latency in groups infused bilaterally into the amygdala with the following drugs: 8OH-DPAT (DPAT), NAN-190 (NAN), norepinephrine (NE), timolol (TIM), SKF38393 (SKF), SCH23390 (SCH), 8-BrcAMP (CAMP), KT5720 (KT), forskolin (FOR), vehicle (VEH) and saline (SAL).

${ }^{*} \mathrm{P}<0.002$ compared to saline control group (two-tailed Mann-Whitney U-test). Only treatments given 0 or $3 \mathrm{~h}$ posttraining were studied. NE caused retrograde facilitation when given $0 \mathrm{~h}$ after training. All other treatments were ineffective. $\mathrm{N}=10-12$ per group.

\begin{tabular}{lcc}
\hline Drug & \multicolumn{2}{c}{ Latency (min) } \\
\cline { 2 - 3 } & \multicolumn{2}{c}{ Time after injection } \\
\cline { 2 - 3 } & O h & $3 \mathrm{~h}$ \\
\hline SAL & 40 & 54 \\
DPAT & 42 & 45.5 \\
NAN & 39 & 40 \\
NE & $180^{*}$ & 40.5 \\
TIM & 43 & 45.5 \\
SKF & 37.5 & 54.5 \\
SCH & 59.5 & 52.5 \\
CAMP & 42.5 & 55 \\
VEH & 45.5 & 48 \\
KT & 46.5 & 44 \\
FOR & 46 & 40 \\
& &
\end{tabular}


diate post-training electroconvulsive shock (14) or intrahippocampal or intra-amygdala infusions of aminophosphonovaleric acid or scopolamine (17).

Aside from immediate post-training facilitatory effect of norepinephrine (Table 2), which confirms earlier findings (18) and has been attributed to interactions with synaptic transmission (17), the amygdala was insensitive to all treatments. Thus, there was no evidence for a role of the cAMP-dependent events regulated by $D_{1}, B$ or 5 HT1A receptors in this structure.

As a consequence, the present findings support the suggestion that the amygdala may play an important role in modulation rather than in storage (19). The amygdala may be important by "adding" aversive or emotional information at the time of consolidation $(7,17)$.

The present findings agree with others in showing that the hippocampus participates in memory consolidation of inhibitory avoidance by a biochemical cascade of events similar to that of various forms of long-term potentiation (15), but do not support a similar mechanism for the amygdala.

\section{References}

1. Ardenghi $P$, Bernabeu $R$, Bevilaqua $L$, Bromberg E, Izquierdo I \& Medina JH (1997). A dopamine D1-cAMP-protein kinase A-CREB-P signalling pathway in the late phase of memory consolidation in the rat hippocampus. Ciência e Cultura, 48 (in press)

2. Ferrer I, Blanco R, Rivera R, Carmona $M$, Ballabriga J, Olivé M \& Planas AM (1996). CREB-1 and CREB-2 immunoreactivity in the rat brain. Brain Research, 712: 159164.

3. Bernabeu R, Bevilaqua L, Ardenghi $P$, Bromberg E, Schmitz P, Bianchin M, Izquierdo I \& Medina JH (1997). Involvement of hippocampal cAMP/cAMP dependent protein kinase signaling pathway in a late memory consolidation phase of an aversively motivated learning in rats. Proceedings of the National Academy of Sciences, USA, 94 (in press).

4. Izquierdo I \& Medina JH (1995). Correlation between the pharmacology of longterm-potentiation and the pharmacology of memory. Neurobiology of Learning and Memory, 63: 19-32.

5. Bernabeu R, Schmitz PK, Faillace $P$, Izquierdo I \& Medina JH (1996). Hippocampal cGMP and cAMP are differentially involved in memory processing of an inhibitory avoidance learning. Neuroreport, 7: 585-588.

6. O'Connell C, O'Malley A \& Regan CM (1997). Transient learning-induced ultrastructural change in spatially-clustered dentate granule cells of the adult rat hippocampus. Neuroscience, 76: 55-62.
7. Cahill L \& McGaugh JL (1996). Modulation of memory storage. Current Opinion in Neurobiology, 6: 237-242.

8. Pohle W, Rüthrich $H L$, Popov N \& Matthies H (1979). Fucose incorporation into rat hippocampus structures after acquisition of a brightness discrimination. Acta Biologica et Medica Germanica, 38: 53-63.

9. Izquierdo I \& Chaves MLF (1996). Synaptic mechanisms in hippocampus, amygdala, septum and entorhinal cortex involved in memory formation, storage and expression. In: Benninger R, Archer T \& Palomo $\mathrm{T}$ (Editors), Dopamine Disease States. Complutense, Madrid, 389-406.

10. Siegel GJ, Agranoff BW, Albers RW \& Molinoff PB (1994). Basic Neurochemistry: Molecular, Cellular and Medical Aspects. 5th edn. Raven Press, New York.

11. Paxinos $G \&$ Watson $C$ (1986). The Rat Brain in Stereotaxic Coordinates. Academic Press, San Diego.

12. Zanatta MS, Schaeffer E, Schmitz PK, Medina JH, Quevedo H, Quillfeldt JA \& Izquierdo I (1996). Sequential involvement of NMDA dependent mechanisms in hippocampus, amygdala, entorhinal cortex and parietal cortex in memory processing. Behavioral Pharmacology, 6: 341-345

13. Bianchin M, Da Silva RC, Schmitz PK, Medina JH \& Izquierdo I (1994). Memory of inhibitory avoidance in the rat is regulated by glutamate metabotropic receptors in the hippocampus. Behavioural Pharmacology, 5: 356-359.
14. Gold PE (1986). The use of avoidance training in studies of modulation of memory storage. Behavioral and Neural Biology, 46: 87-98.

15. Maren S \& Baudry M (1995). Properties and mechanisms of long-term synaptic plasticity in the mammalian brain: relationships to learning and memory. Neurobiology of Learning and Memory, 63: 118.

16. Carew TJ (1996). Molecular enhancement of memory formation. Neuron, 16: 5-8.

17. Izquierdo I, Da Cunha C, Rosat R, Jerusalinsky D, Ferreira MBC \& Medina JH (1992). Neurotransmitter receptors involved in memory processing by the amygdala, medial septum and hippocampus of rats. Behavioral and Neural Biology, 58: 16-26.

18. Liang KC, McGaugh JL \& Yao HY (1990) Involvement of amygdala pathways in the influence of post-training intra-amygdala norepinephrine and peripheral epinephrine in memory storage. Brain Research, 508: 225-233.

19. McGaugh JL, Cahill L, Parent MB Mesches $\mathrm{MH}$, Coleman-Mesches $\mathrm{K}$ \& Salinas JA (1995). Involvement of the amygdala in the regulation of memory storage. In: MacGaugh JL, BermúdezRattoni F \& Prado-Alcalá RA (Editors), Plasticity in the Central Nervous System: Learning and Memory. Lawrence Erlbaum, Mahwah, NJ, 17-39. 